\title{
Seismic Experiments on Spring Vibration Isolation Foundation of Turbine Generator under Frequent Earthquake, Fortification Earthquake and Rarely Met Earthquake
}

\author{
Yanzhi Liü, a Tiejun Qüb \\ ${ }^{1}$ North China University of Technology, 100144, Beijing, China

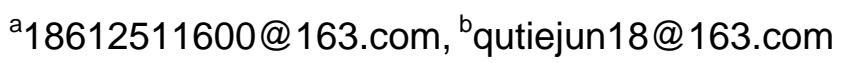

Keywords: Turbine generator foundation; Spring vibration isolated; Pseudo-dynamic testing; Seismic response

Abstract. In this paper, the model tests of 7 degree frequent earthquake, 7 degree fortification earthquake and 7 degree rarely met earthquake are carried out by using the seismic ground motion parameters of a design reference period of 60 years. Displacement of platen and columns, restoring force of foundation and reinforcement strain are obtained, as well as the position and development of cracks. The research shows that the spring vibration isolation foundation has good working performance under earthquake, and the vibration springs has certain effect of decreasing vibration.

\section{Introduction}

In order to verify and supplement theoretical analysis, special tests of turbine generator's seismic performance, need to be carried out. Based on the similarity theory, the 1:8 model of spring vibration isolation foundation of turbine generator is designed to ensure the safety and reliability in the 7 degree frequent earthquake, 7 degree fortification earthquake and 7 degree rarely met earthquake experiments.

\section{Test model}

The test model of this study is composed of reinforced concrete columns, platen, middle platforms and bottom platform. Springs are installed between platen and columns. What's more, anti-skid boards are used to prevent slippage between spring isolators and adjustment liners.

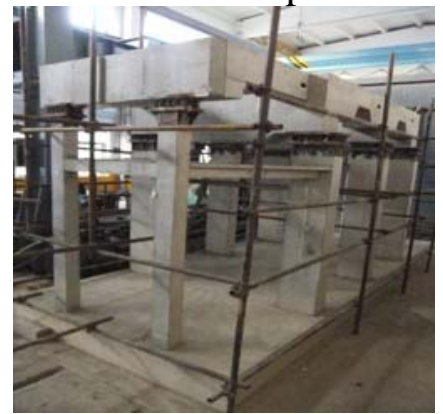

(a)

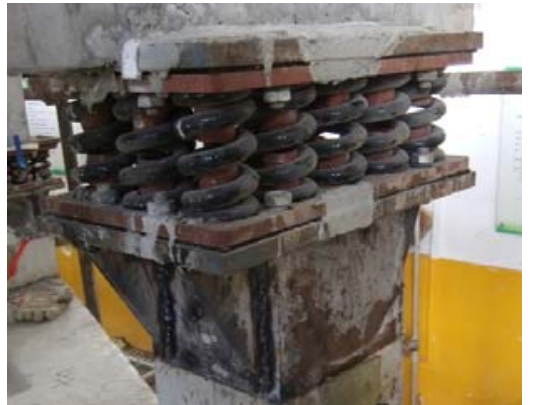

(b)

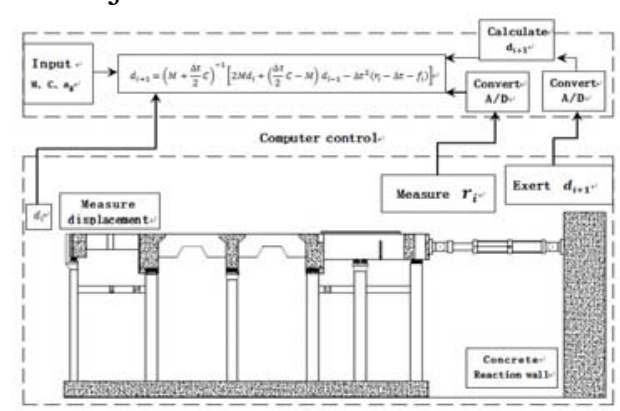

(c)

Fig.1. (a) The model of turbine generator foundation (b) Spring isolator (c) Diagram for this pseudo dynamic test

\section{Test contents}

Pseudo dynamic test can reproduce elastoplastic earthquake response of large scale models by combining computer control and structural test. The force-displacement curves of structures could be obtained by inputting the earthquake acceleration. The whole loading process can be carried out step by step, which leads to more detailed observations of the structural damage process. Diagram for this pseudo dynamic test is presented in Fig.1. 
Artificial earthquake wave. The design reference period of this study is 60 years. Related parameters are shown in Table1. The acceleration time-history curves of frequent earthquake, fortification earthquake and rarely met earthquake are shown in fig.2.

Table1 The maximum of horizontal earthquake influence coefficient and acceleration

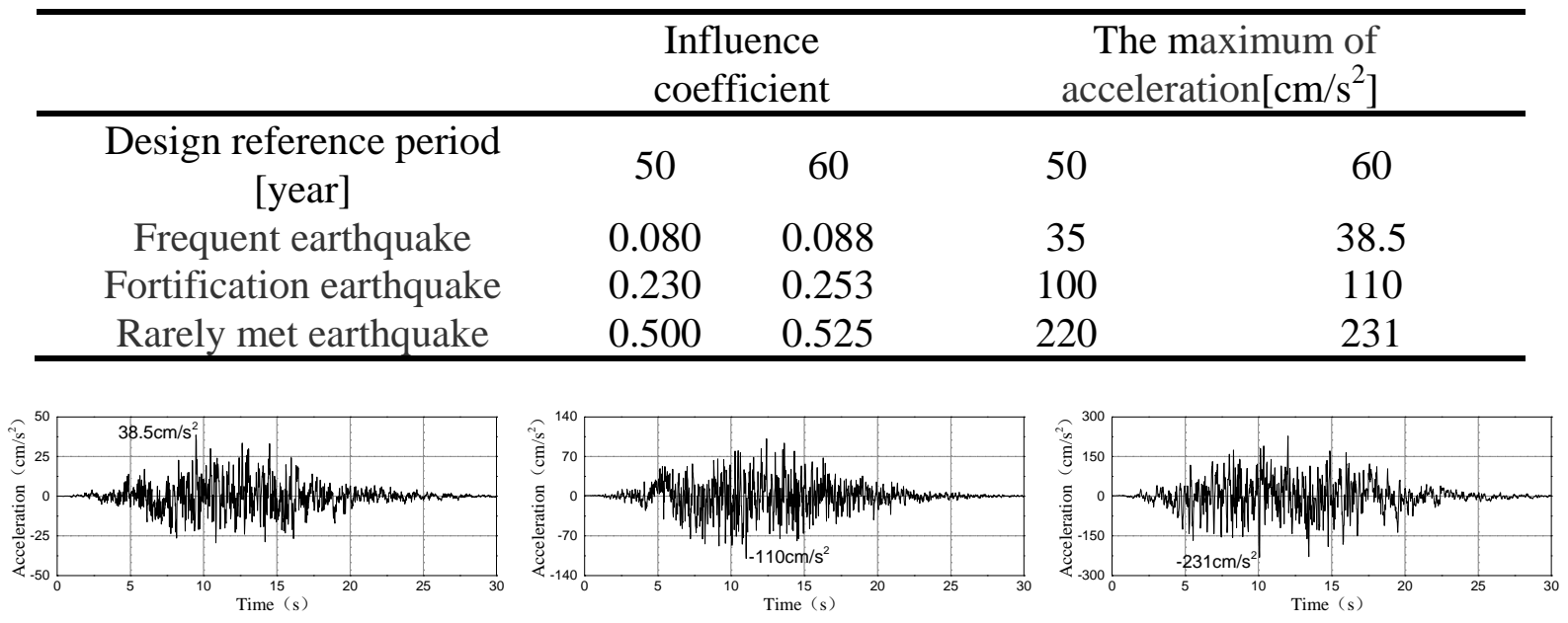

Fig. 2 The acceleration time-history curves of frequent earthquake, fortification earthquake and rarely met earthquake

Principal experimental contents. Platen and column displacement, foundation restoring force and reinforcement strain can be obtained by the tests directly. All the following results are prototype structures obtained from the model test data by similarity transformation.

\section{Test results}

Seismic response of displacement, acceleration, velocity, restoring force. Table 2 shows the maximum of displacement acceleration, velocity and restoring force of prototype structure.

Table2 The maximum of seismic response

\begin{tabular}{ccccc}
\hline & $\begin{array}{c}\text { Displacement } \\
{[\mathrm{mm}]}\end{array}$ & $\begin{array}{c}\text { Acceleration } \\
{\left[\mathrm{m} / \mathrm{s}^{2}\right]}\end{array}$ & $\begin{array}{c}\text { Velocity } \\
{[\mathrm{m} / \mathrm{s}]}\end{array}$ & $\begin{array}{c}\text { Restoring force } \\
{[\mathrm{kN}]}\end{array}$ \\
\hline Frequent earthquake & 14.96 & -0.195 & 0.049 & 2098.00 \\
Fortification earthquake & 42.32 & -0.450 & -0.121 & 4846.00 \\
Rarely met earthquake & 98.00 & -0.893 & 0.292 & 9721.00 \\
\hline
\end{tabular}

Under the effect of frequent earthquake, fortification earthquake and rarely met earthquake, the maximum acceleration response of the prototype structure are $-0.893 \mathrm{~m} / \mathrm{s}^{2},-0.450 \mathrm{~m} / \mathrm{s}^{2}$ and $-0.195 \mathrm{~m} / \mathrm{s}^{2}$, respectively. Therefore, the corresponding magnification factors (the acceleration maximum of seismic response/ that input) are $0.51,0.41$ and 0.39 .

Acceleration of different height positions under 7 degree rarely met earthquake is used for comparison. Take $\mathrm{C} 1$ as an example, the magnification factors of middle platforms beam-column join, the top of column, platen are 0.62, 0.72, 0.74, respectively, while the maximum acceleration response of those are $0.60,0.53,0.52$. The results show that the acceleration of platen is obviously smaller than the top of columns, which turns out that vibration isolators play a protectable role for platen under rarely met earthquake.

The maximum of displacement response of different positions are shown in table3. 
Table3 The maximum of displacement response [mm]

\begin{tabular}{ccccc}
\hline & Plate & Top of columns & Middle platform & Beam-column join \\
\hline Frequent earthquake & 14.96 & 13.15 & 11.71 & 11.68 \\
Fortification earthquake & 42.32 & 37.22 & 32.97 & 35.53 \\
Rarely met earthquake & 98.00 & 87.03 & 75.82 & 81.08 \\
\hline
\end{tabular}

The displacement time-history curves of platen, middle platform, the top of columns under frequent earthquake, fortification earthquake, rarely met earthquake are shown in fig.3. As can be seen in these figures, platen, middle platform, columns have a substantial coincidence of vibration trend under 7 degree frequent earthquake, fortification earthquake, rarely met earthquake.
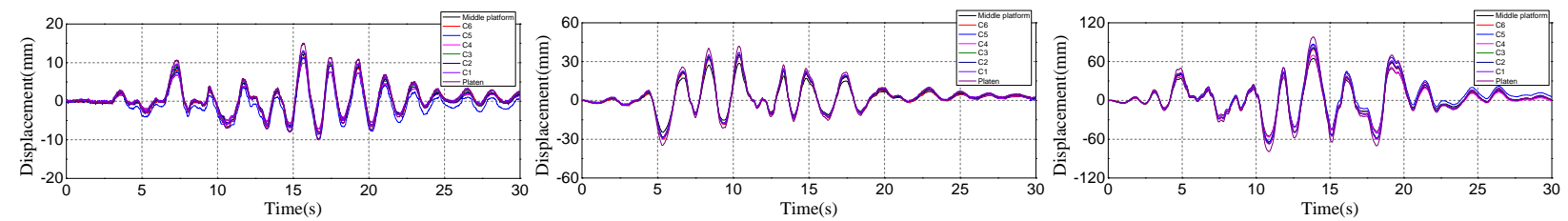

Fig.3 The displacement time-history curves of platen, middle platform, the top of columns under frequent earthquake, fortification earthquake and rarely met earthquake

Inter-story drift. The seismic design code of buildings (GB50011-2010) provides that the limit of reinforced concrete frames elastic inter-story drift is 1/550 under frequent earthquake, and 1/50 under rarely met earthquake. The maximum of inter-story drift of different positions is shown in table4, which indicates that deformability of this foundation meets the requirements of current seismic design code under frequent earthquake and rarely met earthquake.

Table4 The maximum of inter-story drift

\begin{tabular}{|c|c|c|c|}
\hline & $\begin{array}{l}\text { Frequent } \\
\text { earthquake }\end{array}$ & $\begin{array}{l}\text { Fortification } \\
\text { earthquake }\end{array}$ & $\begin{array}{l}\text { Rarely met } \\
\text { earthquake }\end{array}$ \\
\hline Platen to bottom platform & $1 / 1745$ & $1 / 617$ & $1 / 266$ \\
\hline $\begin{array}{l}\text { Middle platform under high Pressure } \\
\text { cylinder to bottom platform }\end{array}$ & $1 / 1438$ & $1 / 511$ & $1 / 222$ \\
\hline $\begin{array}{l}\text { Middle platform under generator to } \\
\text { bottom platform }\end{array}$ & $1 / 1699$ & $1 / 586$ & $1 / 260$ \\
\hline
\end{tabular}

Displacement on the top of columns and maximum deformation of spring. Displacement on the top of columns and maximum deformation of springs are shown in table5. The total deformation of columns under frequent earthquake, fortification earthquake and rarely met earthquake are $14.96 \mathrm{~mm}$, $42.32 \mathrm{~mm}, 98.00 \mathrm{~mm}$, respectively. Compared with displacement on the top of columns, the deformation of spring is smaller. The value of bottom plate displacement is close to zero, which indicates that measures for anchoring bottom plate is reliable.

Table5 Displacement on the top of columns and maximum deformation of springs

\begin{tabular}{|c|c|c|c|c|c|c|}
\hline \multirow[b]{2}{*}{ Columns No. } & \multicolumn{2}{|c|}{ Frequent earthquake } & \multicolumn{2}{|c|}{ Fortification earthquake } & \multicolumn{2}{|c|}{ Rarely met earthquake } \\
\hline & $\begin{array}{c}\text { Top of } \\
\text { columns }\end{array}$ & $\begin{array}{c}\text { Spring } \\
\text { deformation }\end{array}$ & $\begin{array}{l}\text { Top of } \\
\text { columns }\end{array}$ & $\begin{array}{c}\text { Spring } \\
\text { deformation }\end{array}$ & $\begin{array}{c}\text { Top of } \\
\text { columns }\end{array}$ & $\begin{array}{c}\text { Spring } \\
\text { deformation }\end{array}$ \\
\hline 1 & 13.15 & 1.81 & 37.22 & 5.10 & 85.59 & 12.41 \\
\hline 2 & 12.36 & 2.60 & 35.12 & 7.20 & 81.09 & 16.91 \\
\hline 3 & 12.68 & 2.28 & 35.59 & 6.73 & 82.12 & 15.88 \\
\hline 4 & 9.37 & 5.59 & 34.56 & 7.76 & 70.00 & 28.00 \\
\hline 5 & 11.05 & 3.91 & 35.27 & 7.05 & 87.03 & 10.97 \\
\hline 6 & 11.52 & 3.44 & 34.21 & 8.11 & 79.12 & 18.88 \\
\hline
\end{tabular}


Strain of steel bar. The results show that strain of columns root steel bar is larger, while the top is relatively smaller. In addition, the strain of steel bars' on underside of the middle platform is larger than that on the upside; steel bar in beams of platen nearly has no deformation. The maximum strain in C5column root under frequent earthquake, fortification earthquake and rarely met earthquake is about $150 \mu, 390 \mu$ and $740 \mu$ respectively. According to the yield strength and modulus of elasticity, the yield strain of steel bar is $2000 \mu$, which indicates that it is in elastic deformation range under frequent earthquake and fortification earthquake. The steel bars' deformation in rarely met earthquake is lower than its yield strain, which means that, the steel bar has not yielded.

Horizontal resistance of antiskid boards. The anti-skid board, with friction coefficient about 1.5, used in this experiment, is a kind of material of rough textile and modified bitumen. The vertical total force of the upper part of the spring isolator provided by the design data is $63954.8 \mathrm{kN}$, hence friction force is $95932.2 \mathrm{kN}$, which is much greater than the maximum of restoring force $9721 \mathrm{kN}$ under rarely met earthquake. Therefore, it is possible for the connection of the spring isolator and the foundation to resist the horizontal force of the rare met earthquake by relying on the antiskid boards.

Force-displacement curve. Figure4 is the force-displacement curve of structure.

Under frequent earthquake, the restoring force is linear with displacement. And area surrounded by hysteresis loop is very small. During the cyclic loading process, stiffness has little degradation and structure has been in elastic stage.

Under fortification earthquake, the force-displacement curve covers small area of hysteresis loop. During the cyclic loading process, the slope of curve has a decreasing tendency.

Under rarely met earthquake, the slope of force-displacement curve reduces with increase of load and the area surrounded by hysteresis loop is larger than under fortification earthquake. When the load is about $-4000 \mathrm{kN}$, the curve's slope decreases; stiffness also degraded, but the degradation is not sustained. During the experiment process, the displacement of structure returns to zero. What's more, there is no obvious plastic deformation as well as residual deformation.
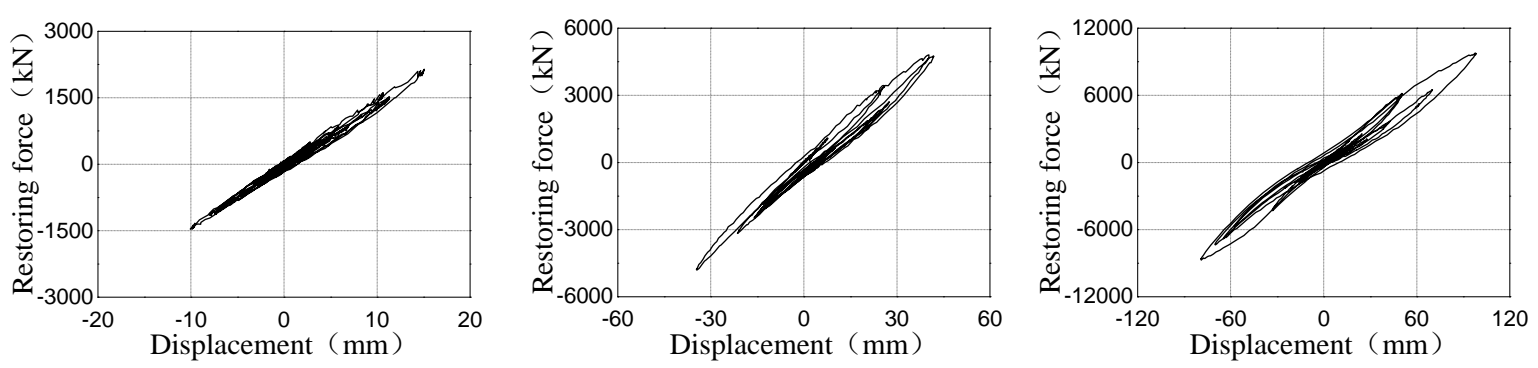

Fig.4 Force-displacement under frequent earthquake, fortification earthquake, rarely met earthquake

The position and development of cracks. The first crack appears in the beam-column joints, and extends as load increases. At 15.76 seconds, the displacement of the prototype is the largest, and the maximum crack width of the beam column joints is $0.05 \mathrm{~mm}$; Crack in the root of the column is $0.02 \mathrm{~mm}$. After the test, the crack is not obvious.

Cracks are mainly distributed in the beam-column joints and some columns' root. Transfixion cracks are not formed. So it can be inferred that structure is basically intact.

\section{Conclusions}

In this paper, 7 degree frequent earthquake, fortification earthquake and rarely met earthquake are carried out by using the design reference period of 60 years. The conclusions are as follows:

Under 7 degree frequent earthquake, the maximum displacement of platen is relatively small, and is still in the elastic deformation range; under 7 degree fortification and rarely met earthquake, the foundation tends to have certain and still in good condition.

Under 7 degree frequent and fortification earthquake, the strain of steel bar is much smaller than its yield strain; under 7 rarely met earthquake, the strain of steel bar of columns has not reached its yield strain, and the damage of structure is slight. Therefore the steel bar can continue to work 
without extra repair, which shows that spring vibration isolator improves the seismic performance of the structure.

\section{Conflict of Interests}

The authors declare that there is no conflict of interests regarding the publication of this paper.

\section{Acknowledgments}

This paper was financially supported by Beijing Natural Science Foundation (8142015) and "Undergraduate training-Approval and research of teaching reform-Experimental spot of educational reform of continuing education in colleges” (Project encoding in the college:15007-8).The authors' deeply express sincere appreciation to them.

\section{References}

[1] GB 50011-2010, Code for Seismic Design of Buildings [S].Beijing: China architecture \& building press, 2011.

[2] JGJ101-96, Specification of Test Methods for Earthquake Resistant Building [S]. Beijing: China architecture \& building press, 1997.

[3] Tiejun Qu, Kun Xiang, Xuejun Yin. Pseudo-dynamic Test of the Anti-seismic Performance of Turbine Generator Foundation [J]. Earthquake Resistant Engineering and Retrofitting. 2013(01):115-119.

[4] Zhubing Zhu, Tiejun Qu. Seismic Input Research on Large Steam-turbine Generator Foundation [J]. Journal of North China University of Technology. 2009, 01:81-84.

[5] Dong An. Experimental Study on Seismic Performance of Spring Vibration Isolation turbine generator Foundation [D]. North China University of Technology, 2010.

[6] Fawei Qiu, Jiaru Qian. Some Applications of Pseudo Dynamic Testing Method[J].Engineering Mechanics. 1999(01): 78-88.

[7] Shizhu Tian, Tong Zhao. Research on Seismic Pseudo Dynamic Test [J]. World Earthquake Engineering. 2001(04): 60-66. 